\title{
MOST SPECIFIC INCONSISTENCIES OF LABOR SAFETY MANAGEMENT SYSTEM IN CONSTRUCTION INDUSTRY ENTERPRISES
}

Indra KARNUPA, Institute of Labor Protection and Civil Defence, Faculty of Engineering Economics and Management, Riga Technical University, Kalku street 1, Riga, Latvia, indra.karnupa@gmail.com

Janis IEVINS, Institute of Labor Protection and Civil Defence, Faculty of Engineering Economics and Management, Riga Technical University, Kalku street 1, Riga, Latvia, janis.ievins@rtu.lv

Inese VILCANE, Department of Work Environment and Safety, Faculty of Economics and Business Administration, Tallinn University of Technology, ivilca@ttu.ee (corresponding author)

The construction industry and the safety of workers in it is also related to the agricultural sector and its development. The construction industry is one of the most dangerous sectors in the world where employees relatively often suffer from accidents. The purpose of this paper is to examine the role of labor safety management systems in construction industry enterprises. The main goal of the study is to detect the most significant inconsistencies in the labor safety management system, to develop the necessary actions and activity, which ensure the elimination of inconsistencies or minimization of their consequences, and also provide an economic benefit for the company. Since the purpose of this study is to ensure that the construction company, knowing the most common weaknesses in the system, is preventive in dealing with these issues.

The study methods used are secondary data analysis, case study and expert observations in ten companies that chooses to implement the OHSAS Standard. A total of 35 external audit reports were analyzed for the period 2008 to 2016. The study examines the role of labor safety management systems in construction industry enterprises. The study identifies the problems and influencing factors associated with implementation and maintenance of the systems. The work analyzes theoretical aspects of the safety culture, its development and choices of the labor safety culture in the organization. Requirements of labor safety legislation in the European Union are reviewed and how these requirements are integrated into Latvian legislation, and specifically in the enterprises of the reviewed sector. The most significant inconsistencies of the labor safety management system was identified and summarized in construction companies.

Keywords: labor safety, management systems, OHSAS, preventive measures

\section{INTRODUCTION}

Many organizations are adapting to the requirements of occupational health and safety management systems worldwide. Despite the considerable acceptance of the systems for managing occupational health and safety in organizations, there is still no clear consensus on their effectiveness (Ghahramani, 2016).

When Latvia joined the European Union, the construction sector became one of the most important sectors in Latvian national economy. The construction industry is one of the most dangerous sectors where employees relatively often suffer from accidents. Rapid ups and downs in the sector's development have adversely affected the industry, both in terms of occupational safety and social welfare. This instability is also a test for employers in the construction sector, whose biggest challenge is to provide jobs in times of recession, and as a result of rapid development, find the workforce that left the country during the recession or work with those who do not have the appropriate skills. Consequently, the employer must be prepared for rapid training of labor force. This, in turn, means that there is a need to create systems for training, awareness and promotion of understanding about work and safe labor methods. Work should be carried out at workplaces on the creation and development of labor safety culture, which would increase the employees' safe behave our and serious attitude towards reduction of possible risk.

The author's opinion on the importance of labor safety in construction industry is that in Latvia it still is not a primary issue, however, some issues are gradually being arranged and overall tendency of these measures is positive. A lot of work is

Copyright (C) 2017 The Authors. Published by Aleksandras Stulginskis University. This is an open-access article distributed under the terms of the Creative Commons Attribution License (CC-BY 4.0), which permits unrestricted use, distribution, and reproduction in any medium, provided the original author and source are credited. 
carried out by the State Labor Inspectorate and other organizations in the sector, creating informative materials and technologically easy tools that the employers can use to raise their knowledge and interest. (LVS OHSAS 1800, 2007)

In order to seriously think about development of labor safety culture in a company, the company management must have a sufficient understanding of its significance and impact on the quality of work carried out by the company, prestige, and customer loyalty. More attention is being paid to the social responsibility in the world. Considering the situation in the sector, entrepreneurs have to think seriously about offering their services outside the Latvian market, which means that the use of safe working methods in companies will become an increasingly important issue. Many international studies show that certification leads to significant increases in abnormal performance on safety, sales growth, labor productivity, and profitability and that these benefits increase (Chris et al., 2014; Lafuente \& Abad, 2017.).

One of the company manager's helper tools is the development and implementation of the Occupational and Safety Assessment Scheme (hereinafter - OHSAS) system in the company in accordance with LVS OHSAS 18001: 2007, introducing the policies and objectives in compliance with legislation and information on occupational risks. "It is intended for use in organizations of all sizes and adapted to different geographic, cultural and social conditions. The success of the system depends on involvement of all levels and functions of the organization, and in particular on senior management. The overall objective is to support and promote good practices of occupational safety and occupational health in order to be balanced with the socio-economic needs. It should be noted that many of these requirements can be dealt with simultaneously or can be returned at any time". (LVS OHSAS 1800, 2007)

There are relatively few companies in Latvia that choose to certify the OHSAS system. The study identifies the place and role of the OHSAS system among companies, whether it is made just to allow the company's participate in tenders of national importance, or it is used as a tool for development of its occupational safety culture. To clarify this, the most frequent inconsistencies in the OHSAS system are analyzed.

\section{MOST SPECIFIC INCONSISTENCIES OF LABOR SAFETY MANAGEMENT SYSTEM}

Starting an analysis of most specific inconsistencies, it is useful to analyze the portrait of the company that chooses to implement the OHSAS standard. Ten companies were selected for the study on random basis. For these companies, the OHSAS standard has been introduced and is assumed to be efficiently maintained already for several certification cycles (one certification cycle is 3 years), which allows us to provisionally predict that the number of inconsistencies should be relatively small.

Of all the companies used in the study, 50\% turned out to meet the criteria of large-sized enterprises and 50\% - of medium-sized enterprises in terms of turnover and the number of personnel. It allows us to draw the first conclusion that OHSAS 18001 is not popular among small businesses. This can be explained as follows:

1) Maintenance of the system requires additional resources, similar to maintaining the work safety system in the company;

2) in particular cases, it requires additional human resources, which in small enterprises automatically imposes additional responsibilities on already existing human resources;

3) Small businesses usually do not start in large and public procurement projects, which could be one of the evaluation criteria for the standard OHSAS 18001 certification;

4) According to the author of the study, the implementation of the OHSAS 18001 standard requires understanding from the manager, first of all what it is and what this system brings to the company. The standard is a builder of a kind of internal culture of work environment, which requires too much resource compared to the income of a small company. It should be reminded that working on the OHSAS standard does not necessarily require spending the resources for certification (if, (indeed, the client does not request an attestation in the form of a certificate issued by a certifying company).

The study methods used are secondary data analysis, case study and expert observations in ten companies that chooses to implement the OHSAS Standard. A total of 35 external audit reports were analyzed for the period 2008 to 2016 . These audits were carried out by 7 auditors, including the author of the study. The audit reports are not evaluated from the aspect which auditor (age, gender, and experience) has recorded the inconsistencies. Based on the fact that the standard and understanding of the standard are relatively similar to all auditors, on which training was carried out, the quality of the auditors' work is continuously monitored by both certification and accreditation.

External or third party audits are carried out by certification companies. The audits are based on randomly selected examples, since the entire OHSAS system cannot be audited within the allocated time. The audit method involves interviewing employees, getting acquainted with the established documentation and attestations of the system maintenance. The work site is also visited during the audit. The date and time of the visit, in contrast with site visits of the State Labor Inspection, are agreed with the client. The audit is not anonymous, names and surnames of the persons being interviewed are fixed. However, it should be remembered that the established system or processes are audited and not how correctly a person works. Based on randomly selected examples, a conclusion is prepared upon completion of the audit regarding the audit findings and the efficiency of the OHSAS system maintenance.

A total of 45 inconsistencies were drawn up in 35 audits. "Inconsistency means nonfulfillment of requirements. Inconsistency may be any deviation from relevant work standards, work practices, procedures, regulatory requirements, OH\&S management system requirements" (LVS OHSAS 1800, 2007). On average per audit, at least one or more inconsistencies are found. 
It should be admitted that the complete analysis lacks the records of inhouse audits of the enterprises themselves, which is provided for by the standard. Attestations of inhouse audits are the company property and are not distributed to certification organizations (can only be acquainted with during the audit). If such information were available, it would be possible to compare how the company arranges the work environment monitoring or how problems are detected, or in the standard language - inconsistencies. It would be therefore clearer to understand whether the OHSAS system is really efficiently maintained and improved. As is often the case, the system is set up for tenders, it functions formally, the documentation is only arranged for visits of external auditors. Then, of course, the implementation of the standard does not justify itself, showing that the company has no understanding of its application and lack training. As any tool for improvement of processes, OHSAS also requires the awareness, understanding how to deal with and use it. Any system, culture created by the company, begins with top management.

Grouping the inconsistencies by the absolute majority and assigning them places I to $\mathrm{V}$, for which clauses of the standard the inconsistencies are most often recorded is shown below.

As can be seen after summarization of the study data, relatively more frequently, or occupying the first place, inconsistencies are identified and recorded relating to clause 4.3.1. of the standard: identification of hazards, risk assessment and determination of supervisory measures.

The second place, according to reports on inconsistencies prepared by enterprises surveyed in the study, is taken by the management reports, which should be recognized as an unexpected conclusion. It is a document drawn up annually by senior management. If the system is maintained for several cycles and the auditors review it annually, it is practically impossible to compile it incorrectly. However, the result of the analysis proves the opposite.

The third place among the detected inconsistencies belongs to clause 4.5.2. - Compliance assessment.

The conclusion on this established inconsistency is that it is only recorded if the assessment is not carried out at all and not if made incompletely.

Fourth place-clause 4.4.2. Competence, training and awareness.

It should be noted that getting acquainted with the instructions is not the only way of training. The OHSAS system also provides training on OHSAS policies, goals, and work culture. However, $99 \%$ of inconsistencies with this clause of the standard directly relate to incorrect briefing on instructions or missing briefing at all.

Finally, the fifth place-clause 4.3.3. Objectives and programme(s). It should be admitted that these inconsistencies are also surprising since setting targets is the basis of the standard, which results from the policy. The inconsistencies are only recorded if evidences of existence the objectives and the programme is not fully available. (Certified companies audit reports)

Conclusions on the fixed inconsistencies:

1) Relatively low number of fixed inconsistencies for clause 4.4.6. "Operative management" of the standard, which includes the implementation and maintenance of supervisory measures, since only those controlled who will be fulfilled!

2) No inconsistencies found for clause 4.4.3.2. "Participation and Consultation".

If an enterprise ignores the elimination of inconsistencies, it will receive a warning about suspension of the certification process and cancellation of the certificate. However, such cases are extremely rare. They can only happen if the company has certified the system only for a specific project and upon its completion decided not to continue the certification since it, for example, does not pay financially. This could be the most common reason when a manager does not understand the benefits of this system and simply wishes to reduce the company's costs. This, of course, does not mean that the company cannot operate internally according to the principles of the standard.

All detected inconsistencies discrepancies are given an elimination period of 90 calendar days. Attestation of inconsistencies elimination should be submitted to the auditor who shall approve the performance of corrective and/or preventive actions.

In addition to inconsistencies, observations are shall be also recorded in the audit. Audit observations or establishment of facts shall be recorded in the audit report in cases when no sufficient evidences exist of a complete failure to meet requirements of the standard, when they are not systematic, which would be automatically defined as an inconsistency. In short, observations are potential inconsistencies that the auditor is paying attention to. It remains up to the company whether these observations are taken into account and improvements are made in the system. If during a follow-up visit, which usually takes place at 1-year interval, the same observations are again detected, an inconsistency report is shall be drawn up.

The summarized data shows average 4 observations per audit. However, it is a mathematical estimate while the actual number of observations is not predictable, it depends on the number of auditors in the team, time allocated for the audit, specificity of the company's work site, selected objects, and other variable circumstances.

First place or $71 \%$ cases of the reviewed audit reports: observations on operative management according to clause 4.4.6.of the standard.

Second (established in $65 \%$ of the reviewed audit reports), third (54\%) and fifth (34\%) place, like in analysis of inconsistencies - observations according to the same clauses of the standard.

Fourth (established in $40 \%$ of the reviewed audit reports) place: observations associated with the document management. (Certified companies audit reports)

Conclusions on observations:

1) Like with inconsistencies, no observations according to clause 4.4.3.2. - Participation and consulting. 
2) On management reports, clause 4.6. - there is no observation that suggests that auditors have not gone into the content of the management report, although it is one of the merging documents submitted to top management - a report on performance of the system and events during the reporting period.

3) Relatively many of the observations are presented in their content as the inconsistencies, which, not knowing all collateral circumstances, cause questions why the i8nconsistency was not formalized.

The analysis revealed which third-party audits most often detected inconsistencies and observations. Taking into account the author's practical experience in certification audits, when drawing conclusions about the most frequent inconsistencies in construction companies, the author of the study proposes not to single out certain inconsistencies (drawn up reports on inconsistencies for which corrective and/or preventive actions should be taken within terminated time) and observations (audit facts fixed in the audit report with no requirement for immediate confirmations of corrective/preventive actions). Since the purpose of this study is to ensure that the construction company, knowing the most common weaknesses in the system, is preventive in dealing with these issues.

\section{Research results}

ISO series standards is based on Deming methodology principles. The authors of the study identifies, which of Deming methodology elements are not fulfilled at enterprises or are fulfilled partly, see Figure 1.

As seen on Figure 1, most inconsistencies are found in first stages of the cycle, which is logical: if processes are planned incorrectly or erroneously, the entire system does not work in accordance with the plan. In the check stage, it is relatively difficult to examine whether operation meets the plan if planning and work processes are not strictly stipulated and documented. The planning process efficiency depends on involvement and attitude of top management.

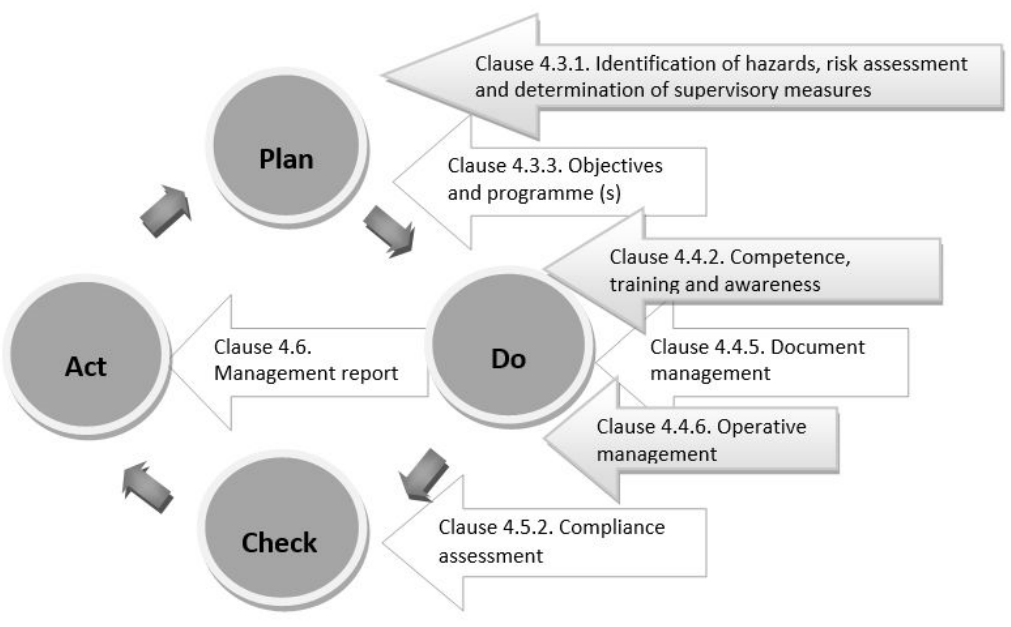

Figure 1. Identification of OHSAS systems weaknesses in construction companies according to Deming methodology (analysis findings)

The planning process starts with the company's OHSAS policy, which indicates the general intentions and progress associated with its implementation in relation to OHAS system. The policy must be adapted to the nature of the company's activities and the scope of work environment risks, providing a framework for the development and review of OHSAS objectives. The policy must include commitments to comply with existing legal requirements and other requirements that are binding on the company, and commitment to prevent injuries and ill health, and to continually implement and improve the system. The policy must be available to the company employees and stakeholders. Each employee must be aware of own individual obligations in OHSAS system. (LVS OHSAS 1800, 2007)

A. Planning and OHSAS standard clause p.4.3.1. Identification of hazards, risk assessment and determination of supervisory measures, possibilities to eliminate inconsistencies (LVS OHSAS 1800, 2007):

1 management is informed about significant risks implements adequate control;

2. Management acknowledges its liabilities and commitments by adequate action -is informed about essential issues of occupational health and labor safety;

3. Management provides consultations with employees on occupational health and labor safety issues;

4. Management timely identifies unsafe behaviour, takes preventive actions.

5. Systematic approach to management of labor safety systems - identification, assessment and monitoring of risks are carried out on a regular basis (for each new project);

6. Subcontractors meet the same requirements - shall preventively incorporate agreements in the cooperation contracts;

7. Documented information (evidences of risk identification and assessment) is readily available; 
8. Employees understand the risks and their control options they deal with town workplaces - regular check;

9. Employees understand their role at workplaces and engage in labor safety issues - they are regular check;

10. Identification of hazards that can occur at and outside the workplace (including getting to work) - for each work site;

11. Identification of all machinery, equipment, rigging, and assessment of risks caused by them;

12. Measurement of execution of planned measures in order to control their compliance, "learning from mistakes";

13. Occupational health and labor safety issues must be regularly considered as one of the issues at the management meetings, participation of the labor safety specialist in the meetings is compulsory;

14. At workplaces, most likely in offices or mobile wagons, labor safety information boards can placed for builders, for example, with information on days without accidents or photo fixation of risks identified by workers. Worker labor safety sheets may be created, for example, in one of the existing smartphone applications where pictures can be sent. (HSE, 2013)

B. Elimination or reduction of inconsistencies with the standard clause 4.4.2. "Competence, training and awareness". Competence can be described as a person's training, skills, experience and knowledge such person can use to safely perform its tasks (LVS OHSAS 1800, 2007):

1. Everyone understands the risks in the construction industry and understands how to manage them;

2. Everyone understands the possible consequences if the employee departs from certain procedures;

3. Main work managers -"key people" - are identified and their roles and responsibilities are clearly defined;

4. People are provided with the necessary training, skills, knowledge and experience to fulfil their duties, and sufficient time is given for it;

5. Training is usually carried out during working hours and paid by the employer;

6. Knowledge acquired in training, examples of good practice are communicated internally to all employees. (HSE, 2013)

It should be taken into consideration that training must be organized in accordance with employees' responsibility, their abilities, language skills and writing skills. Different risk levels in various professions must also be taken into account.

C. Elimination or reduction of inconsistencies associated with the standard clause 4.4.6. Operative Management, resulting from activities and processes shown on Figure 1 in connection with hazard identification (LVS OHSAS 1800, 2007):

1. Operative supervisory measures shall be implemented systematically, their regularity shall be determined by the company itself;

2. Evidences of implementation of the measures shall be available to the management and staff;

3. Supervisory measures shall be applied to the procured goods, equipment and services;

4. Supervisory measures shall be applied to the contractors and other visitors of construction sites;

5. Criteria shall be identified of what will be checked in these supervisory measures, focused at achieving the OHSAS objectives and observing the policy. (HSE, 2013)

Conclusions resulting from the standard clause 4.4.6. Operative Management, planned activities must be implemented and their implementation efficiency must be controlled.

Summarizing all of the above, the author presents a summary of main advantages of the OHSAS system. From the standpoint of business, it is possible to distinguish 4 basic values that are obtained in the creation, maintenance and continuous improvement of the system:

1. Compliance with requirements of existing regulatory enactments - confidence appears in compliance of the company with the requirements specified in laws and regulatory enactments in the field of labor safety and occupational health.

2. Company's reputation - in the eyes of customers, suppliers, institutions and investors the company acquires image of a solid and reliable enterprise.

3. Work delays and injuries -reduction in downtime and production breaks, increasing labor productivity. Reduction in the number of accidents at work. Improvement of employees' working and living conditions. Reduction in insurance costs.

4. Employees' involvement - Improved understanding of safety and increased motivation of employees for work safety improvements. Improved relations with employees and supervisory authorities.

Existence of the system in a company helps to identify risks associated with the impact of the company's working conditions on health and life of employees and choose the best way to manage and reduce these risks. The system not only allows to control the state of labor protection in the company but also to assess its efficiency, as well as contributes to its continuous development and improvement.

\section{CONCLUSIONS AND DISCUSSION}

1. The most common reasons for certification of OHSAS systems are government procurements that include such assessment criterion. Systems certified for this purpose are often not maintained efficiently and do not reach the objective of the standard.

2. The rules for registration of construction merchants have been developed where one of the quality management systems has been introduced as one of the criteria for the assessment of sustainability, including the system of labor safety and occupational health management. It would possibly promote the implementation of OHSAS standards. However, the author evaluates it as a negative aspect since, as mentioned above, systems introduced for this purpose do not justify the objective. The implementation of standards is a voluntary step and should remain such. 
3. Construction is one of the most important sectors in the economy, which still has a high level of shadow economy, unregistered employment, long subcontracting chains, which weaken the safety of the work environment.

4. The main accidents take place due to insufficient control of processes and shortcomings in the organization of work, as well as irregular inhouse supervision of work environment. Only that controlled is executed!

5. The company's labor protection issues can be successfully arranged through the implementation of a safety and occupational health management system, which is a special management system for use in the company with the aim of achieving a high level of labor safety and occupational health.

6. When analyzing the audit reports of construction companies, it turned out that none of the companies met the criteria for a small business, which suggests that OHSAS 18001 is not popular among small businesses.

7. Analysis of the company under investigation shows that the knowledge of existence or implementation of the standard is relatively low.

8. As one of the reasons why the OHSAS standard is not certified, the company management often believes that this measure is costly and requires a large administrative resource.

9. In external audits, most often inconsistencies are found based on analysis results and respective reports are drawn up in relation to the following clauses of the standard:

- 4.3.1. Identification of hazards, risk assessment and supervisory measures. It means that identifying and assessing the risks of the work environment, as well as imposing supervisory measures, is a weak point. Unfortunately, the audit reports do not indicate whether these work environment risks are assessed by a competent specialist/institution or the labor protection specialist of the construction company itself.

- Second place: formalized inconsistencies in relation to the standard clause 4.6. "Management Report".

- Third place by the number of detected inconsistencies: clause 4.5.2. "Compliance assessment".

10. The authors proposes not to separate the inconsistencies and observations, since the objective of the study is to ensure that the construction company, knowing the most common weaknesses in the system, would be preventive in solving these issues. Consequently, the following problems (inconsistencies) are most often identified in the OHSAS system:

- hazard identification, risk assessment and determination of supervisory activities in accordance with OHSAS 18001, clause 4.3.1;

- operative management according to OHSAS 18001, clause 4.4.6;

- competence, training and awareness according to OHSAS 18001, clause 4.4.2.

11. The audit reports of the analyzed companies included no formalized inconsistency in relation to clause4.4.3.2. "Participation and Consultation". The results of the company survey indicate that employees are inert about their ideas about ways to improve their working conditions, perhaps through the lack of awareness about such opportunity. Managerial personnel knows that it is necessary to involve employees in assessment of work environment risks.

12. The most frequently detected inconsistencies are in the first stages of the "Deming Circle" cycle, which means that the system does not work as planned through in correct or incorrectly or erroneous planning of processes. The efficiency of the planning process depends on involvement and attitude of senior management.

13. Control of the planned activity is important in order to achieve the planned objectives or reduce the identified risks and resources invested to justify the existence of the system. By investing more in relatively preventive measures, in the operative management process, the costs must decrease - reducing the number of errors, reducing the cost of accidents while not only the cost item but also actual savings appear in the OHSAS system. The biggest savings are accidents, human health and life.

14. The OHSAS system shall be applicable to the activity supervision of all parties involved, including subcontractors.

\section{REFERENCES}

1. Latvian certified companies audit reports, unpublished data, period 2008-2016.

2. Chris, K.Y.Lo, Pagell, M., Fana, D., Wiengartenc, F., Yeungd, A. C.L. 2014. OHSAS 18001 certification and operating performance: The role of complexity and coupling. Journal of Operations Management, Vol. 32 (5), pp $268-280$. https://doi.org/10.1016/j.jom.2014.04.004

3. Construction Businesses classification rules. (2016). Cabinet of Ministers regulations No. 211, from 12.04.2016. Riga. Available at https://likumi.lv/ta/id/281521-buvkomersantu-klasifikacijas-noteikumi (Accessed on 10/05/2017)

4. Health and Safety Executiv (HSE). 2013. Managing for Health and Safety. Crown copyright, 62 p. Available at http://www.hse.gov.uk/pubns/priced/hsg65.pdf (Accessed on 10/06/2017)

5. EU-OSHA. 2013. European Agency for Safety and Health at Work, 2013. EU-OSHA Priorities for occupational safety and health research in Europe: 2013-2020. Luxembourg.

a. Ghahramani, A. 2016. Factors that influence the maintenance and improvement of OHSAS 18001 in adopting companies: A qualitative study. Journal of Cleaner Production, Vol. 137, pp 283-290. https://doi.org/10.1016/j.jclepro.2016.07.087

6. Lafuente, E., Abad, J. 2017. Analysis of the relationship between the adoption of the OHSAS 18001 and business performance in different organizational contexts. Safety Science, Vol. 103, pp 12-22. https://doi.org/10.1016/j.ssci.2017.11.002

7. LVS OHSAS 18001:2007. Occupational health and safety management systems. Requirements. 32 p. 